\title{
Study of surface quality using quasi-optimal correlation algorithms
}

\author{
Nicolay $\mathrm{V}$. Nosov ${ }^{1, *}$ \\ ${ }^{1}$ Samara State Technical University (SamSTU ), Mechanical Engineering Technology Dep., RF
}

\begin{abstract}
The article proposes a new approach for evaluating roughness of the profile surface of gas turbine engine blade airfoils after vibratory polishing. An optical electronic unit was used to study microgeometry of blade suction and pressure sides: video imagery of the surface was processed using computer methods to obtain the average amplitude of the autocorrelation function variable component. The applied optical electronic method of evaluating microgeometry of compressor/turbine blades allows obtaining fields of surface roughness and tension concentration coefficients as well as analyzing the finish machining technology to a greater depth.
\end{abstract}

\section{Introduction}

Nowadays, the machine building technology takes on a new level which requires creation of a scientific basis for systematic development of new technological processing and control methods. Such methods include mechanical, physical, and chemical methods to ensure required operation qualities of gas turbine engine (GTE) parts as well as to develop a module-based principle of technological process organization.

A particular attention is given to development of new research areas such as computer-based smart process environments or diagnostic \& control systems for figurine-shaped parts. Progress in this area can substantially advance the methodology of GTE surface control.

Development of modern methods and means of surface quality technical control using roughness data (surface microgeometric deviations) obtained with computer-based technologies is one of the greatest challenges of the modern machine building industry.

\section{Research objective}

One of the most important characteristics of the GTE blade surface quality is a microrelief of its working surface: reliability and durability parameters of many blades depend on a pattern of microgeometric deviations of their working surfaces [1]. It is known that the smoother is the surface, the higher is fatigue resistance of the part; many studies show that fatigue fracture nuclei first appear on the part surface. Surface roughness areas are hotspots of tensions and are one of the reasons for fatigue resistance degradation: tension at the bottom of a groove mark is 2-2.5 times higher than average on the surface layer.

\footnotetext{
* Corresponding author: nosov.nv@samgtu.ru
} 
Experimental results reveal that roughness decrease from $R a=0,74 \mu \mathrm{m}$ to $R a=0,74 \mu \mathrm{m}$ increases fatigue strength limit of a specimen by $14 \%$ on average and prolongs its service life more than three times.

\section{Solution method}

Creating modern systems of technical quality control and a methodological basis for researching microgeometric deviations of figurine machine part surfaces in production environment via development of an optical electronic information measurement system (IMS) is a challenging issue.

This problem includes a number of requirements than modern portable surface microrelief measurement devices [2] must meet. Such devices must be compact, produce real-time measurement data without physical contact in a production environment, allow digital processing of the produced data and evaluating microreliefs of figurine surfaces, such as inner cavities of small orifices or working surfaces of molds and dies [3, 4]. Moreover, metrological characteristic of such measurement devices must also be constant regardless of changes in the production environment; finally, the devices must be provided with an energy saving mode.

Existing methods and measurement means of microrelief parameters $X_{\mu i},(i=1, \ldots, r)$ do not allow reducing measurement error below the order of a few tens percent; therefore the objective of this study is development of quality control systems and a methodological basis for research of microrelief of figurine surfaces in a production environment using an optical electronic information measurement system (IMS).

\section{Theoretical basis}

The IMS evaluates the microrelief of a studied surface by means of comparing the surface with images of reference surfaces with roughness parameters defined using standard methods [5] and known. As a result, the studied surface is matched with a certain reference surface with a preset recognition probability. This method allows optimally solving the task using a signal-matched 2D spatial filter which response can be defined as following:

$$
y\left(n_{1}, n_{2}\right)=\sum_{k_{1}=-\infty}^{\infty} \sum_{k_{2}=-1}^{\infty} u\left(k_{1}, k_{2}\right) x\left[k_{1}-\left(n_{1}-n_{01}\right), k_{2}-\left(n_{2}-n_{02}\right)\right] .
$$

Equation (1) is a $2 \mathrm{D}$ convolution of signal $u\left(k_{1}, k_{2}\right)$ and the filter impulse characteristic $x\left[k_{1}-\left(n_{1}-n_{01}\right), k_{2}-\left(n_{2}-n_{02}\right)\right]$. The impulse characteristic is produced from the expected 2D signal by means of reflecting it relative to the reference axes $n_{1}$ and $n_{2}$ and shifting the reflected signal toward the input by $n_{01}, n_{02}$ counts. The output $y\left(n_{1}, n_{2}\right)$ will be proportional to the correlation function of the $2 \mathrm{D}$ input signal, and the maximum signal/noise ratio will be achieved at the filter output.

In the original half-toned frame sized $K_{1} \times K_{2}$ pixels, a strip $N_{2}$ pixels wide is highlighted, beginning with the first line. The reference image sized $N_{1} \times N_{2}$ pixels is inserted in the center of this strip. Then the reference image is moved along the strip with 1 pixel steps, beginning from the leftmost position. Whenever the reference image $u\left(n_{1}, n_{2}\right)$ 
is superimposed onto the current fragment of the half-tone image $x\left(n_{1}, n_{2}\right)$, a correlation coefficient is calculated using the following formula:

$$
r_{x y}\left(k_{1}, k_{2}\right)=\frac{\sum_{n_{1}=0}^{N_{1}-1} \sum_{n_{2}=0}^{N_{2}-1}\left(u\left(n_{1}, n_{2}\right)-m_{u}\right)\left(x\left(n_{1}-k_{1}, n_{2}-k_{2}\right)-m_{x}\right)}{\sigma_{1} \sigma_{2}},
$$

where $\left(n_{1}, n_{2}\right)$ are element indices in the reference image window, $\left(k_{1}, k_{2}\right)$ are reference image coordinates inside the search area $K_{1} \times K_{2}, \sigma_{1}$ and $\sigma_{2}$ are standard deviations of $u\left(n_{1}, n_{2}\right)$ and $x\left(n_{1}, n_{2}\right)$ values from their expected values $m_{u}$ and $m_{x}$. After the correlation coefficients are calculated for the first line, they are calculated for the next line of the same format but shifted one pixel below. In the center of this new strip a new reference image of the same size is inserted, and the same procedure is performed. After processing the entire image, a matrix $M_{1} \times M_{2}$ of correlation coefficients $-2 \mathrm{D}$ correlation function is formed.

Analyzing the equation (2), it is possible to notice that signals $x\left(n_{1}, n_{2}\right)$ and $u\left(n_{1}, n_{2}\right)$ are multiplied by the influence function $f_{6 \pi}(\Delta \Phi, \Delta \alpha)$

$$
r_{x u}\left(k_{1}, k_{2}\right)=\frac{\sum_{n_{1}=0}^{N_{1}-1 N_{2}=0} \sum_{n_{2}-1}^{N_{2}}\left(u\left(n_{1}, n_{2}\right)-m_{u}\right) f_{6 r l}(\Delta \Phi, \Delta \alpha)\left(x\left(n_{1}-k_{1}, n_{2}-k_{2}\right)-m_{x}\right) f_{6, l}(\Delta \Phi, \Delta \alpha)}{\sigma_{1} f_{6 l}(\Delta \Phi, \Delta \alpha) \sigma_{2} f_{6 l}(\Delta \Phi, \Delta \alpha)} .
$$

As the above expression shows, its structure corresponds with the structure of expression (1), and the influence function is reduced.

Known quasi-optimal correlation algorithms and criterial functions were analyzed in order to quicken the calculation procedure. The analysis has shown the most promising to use are twin criteral functions and binary images

$$
\left|\begin{array}{ll}
F_{1,1}(\Delta) & F_{0,1}(\Delta) \\
F_{1,0}(\Delta) & F_{0,0}(\Delta)
\end{array}\right|,
$$

where $\Delta$ is a relative image shift, $F_{i, j}(\Delta), \mathrm{i}, \mathrm{j}=0,1$ is a number of matched elements of a known intensity. A correlation extreme algorithm

$$
R_{\gamma}(\Delta)=\frac{1}{N} \sum_{i=0}^{2^{n-1}} F_{i i},
$$

where $N$ is a number of compared elements in the reference and the current image fragments, was used to achieve the fastest calculation rate.

\section{Experimental results}

Profile roughness of turbine 1st stage blade airfoils made without allowance (ЖС6ФУ material) after vibratory polishing using a ЛВП-4 machine was studied. The movement path of a blade during polishing is a result of geometric addition of mutually perpendicular 
oscillations generated by two crank mechanisms and is shaped as a mesh with controlled parameters, geometrically complex and practically nonreproductible. Such movement path allows creating a uniform microgeometry over the surface of the pressure and suction sides of the blade. Vertical and horizontal oscillation modes directly influence the processing capacity and dynamic loads appearing in the oscillating system. Usually, the oscillation frequency is taken as $20-25 \mathrm{~s}^{-1}$ and the amplitude as $5-10 \mathrm{~mm}$ which results in the machining rate of $30-120 \mathrm{~m} / \mathrm{min}$.

The machining process simulation has shown the maximum machining capacity is provided by a discrepancy in the proportion of frequencies of figures $\omega_{\mathrm{o}}=\omega_{\mathrm{h}} / \omega_{\mathrm{v}}$, where $\omega_{\mathrm{h}}$ is frequency of horizontal oscillations, $\omega_{\mathrm{v}}$ is frequency of vertical oscillations. The $1 / 2 \leq$ $\omega_{0} \leq 1$ frequency range was studied. By setting equal rotation speed of two adjacent figures within ranges: $\mathrm{B}_{1}=1 / 2, \mathrm{~B}_{2}=3 / 5, \mathrm{~B}_{3}=2 / 3, \mathrm{~B}_{4}=3 / 4, \mathrm{~B}_{4}=4 / 5, \mathrm{~B}_{5}=5 / 6, \mathrm{~B}_{6}=1$, the following dependency is obtained:

$$
\operatorname{tg} \omega_{0}=\frac{(\operatorname{Cos} B i+\operatorname{Cos} B i+1) \omega o-(B i \operatorname{Cos} B i+B i+1 \operatorname{Cos} B i+1)}{(B i \operatorname{Sin} B i+B i+1 \operatorname{Sin} B i+1)-(\operatorname{Sin} B i+\operatorname{Sin} B i+1) \omega o} .
$$

The first part of the equation is a hyperbola, the second one is a tangensoid. By solving this equation for $\omega_{\mathrm{o}}$, we obtain the following series of frequency proportions: $0.543,0.617$, $0.704,0.763,0.833,0.917$.

In our case, turbine 1 st stage blades were machined using $\omega_{\mathrm{o}}=0.833$ abrasive tapes in two 2 steps: Step 1 П8 63C 16П MA and step 2 П8 63C 6H MA. Machining modes: polishing rate is $30 \mathrm{~m} / \mathrm{min}$, vertical movement range is $4-6 \mathrm{~mm}$, horizontal movement range is $3-5 \mathrm{~mm}$, machining cycle duration is $12-17 \mathrm{~s}$, saddle pressure in the machining zone is $0.4-0.6 \mathrm{MPa}$.

An optical electronic unit was used to study microgeometry of blade suction and pressure sides. The unit [6] (fig. 1) includes the following components: 1-studied surface, 2 - television camera with a CCD sensor, 3-analog to digital converter, 4-memory storage, 5-device for setting window coordinates and sizes for transformation of the input halftone surface image to a binary image as well as for setting reference image size in the binary image, 6-digital computer, 7-device for setting coordinates of the current binary image fragment, 8 - correlator and software for processing of video imagery of studied surfaces.
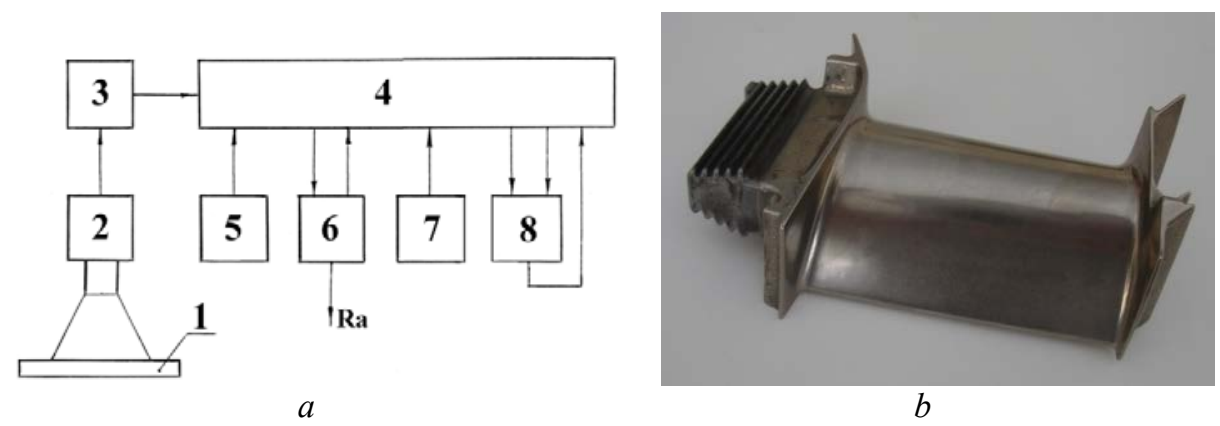

Fig. 1. Diagram of a unit (a) for researching blade surface microgeometry (b) of the 1st stage of an aircraft engine turbine

It is known that surface microgeometric parameters must be uniform over the entire blade surface. Let us agree that uniformity of the surface roughness parameters creates an equiaxial structure and excludes one-directional roughness. For this purpose, an electronic image was rotated by $90^{\circ}, 180^{\circ}$ and $270^{\circ}$, and autocorrelation surface 
parameters were defined. Matching of their values with a 5\% tolerance indicates presence of a certain structure on the blade surface.

Blade surface spots after vibratory polishing were analyzed. Fig. 2. shows half-tone and binary images of the selected surface area, a correlation surface and the correlation coefficient change diagram for this area [7].

The surface area format stored in the computer memory was $320 \times 240$ pixels in this case. Processing of the experimental results has shown that the average of the variable component of the correlation function calculated for 30 images is $U c p=23.1$ rel. units.
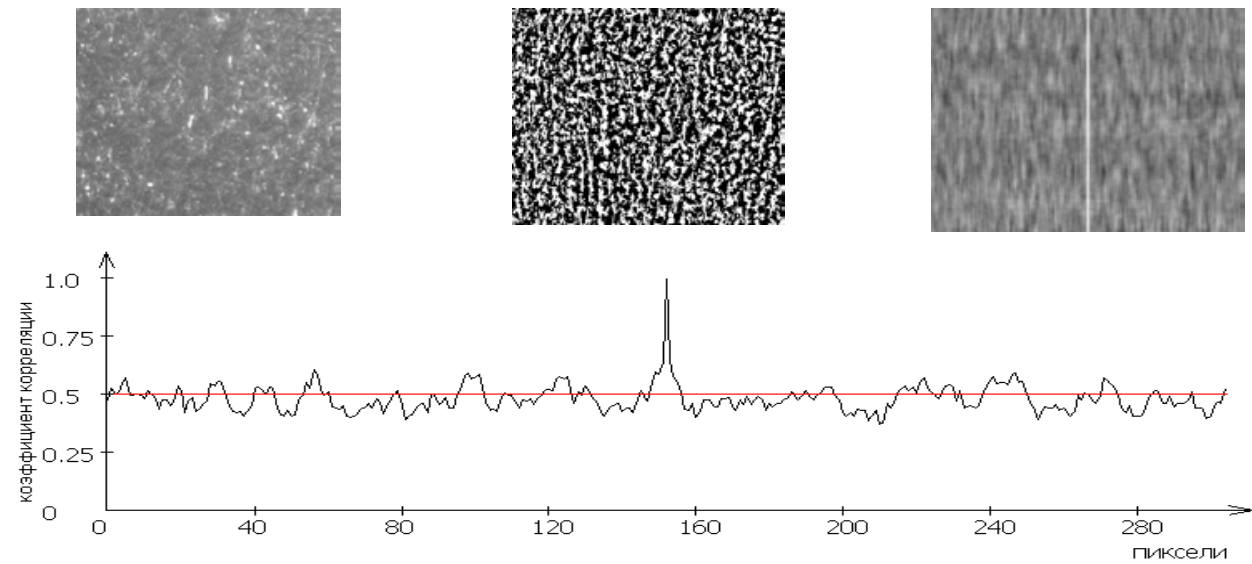

Fig. 2. A half-tone image of a blade surface area, a binary image of this area; a correlative surface; correlative coefficient change

If the studied surface structure (roughness) recognition probability is set to $P=0,99$, the following expression was obtained for the confidence interval:

$$
I_{\beta}=\left(0.09 \times U c p^{3}-4.2 \times U c p^{2}+68.5^{\times} U c p-314.9\right) \times 10^{-2} \text { rel. units, }
$$

and for dependency of a structure with roughness of $R a=f(U c p)$ - the following expression:

$$
R a=0,013 \times U c p-0.078 \mu \mathrm{m} .
$$

By inserting the obtained value $U c p$ into the formula, we find that $I_{\beta}=0.77$ rel. units. Consequently, $U c p_{\min }=22.33$ rel. units, and $U c p_{\max }=23.87$ rel. units. Using the expression for calculation of $R a$ of the blade airfoil surface has produced the following results: $R a=0.22 \mu \mathrm{m}, R a_{\text {min }}=0.219 \mu \mathrm{m}$, and $R a_{\text {max }}=0.221 \mu \mathrm{m}$. Roughness on the suction side is $15 \%$ higher than on the pressure side.

Fig. 3 shows roughness fields for roughness of pressure and suction surfaces of a turbine 1 st stage blade after vibratory polishing with abrasive tapes in one step П8 63C $16 \Pi$ MA. 


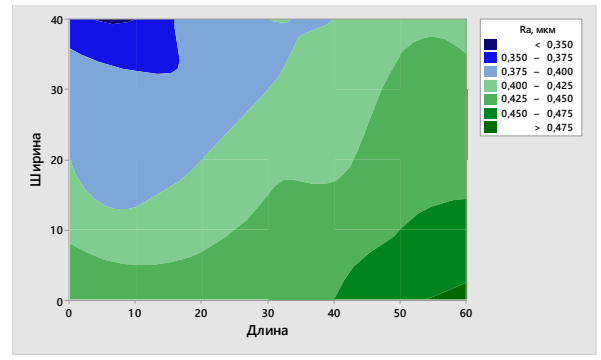

$a$

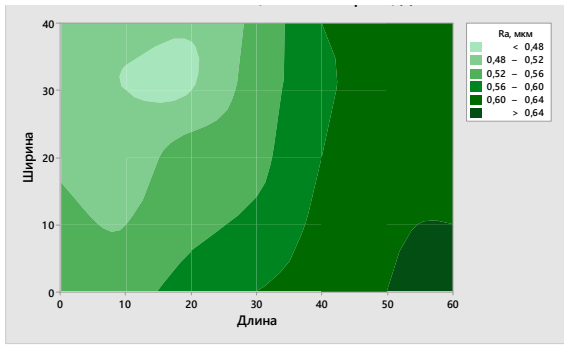

$b$

Fig. 3. Surface roughness fields for a turbine 1 st stage blade after the 1 st step: a-pressure side, bsuction side.

\section{Conclusion}

The study proves that the optical electronic method for evaluation of turbine blade surface quality allows developing surface roughness fields and use them to better analyze the vibratory polishing technology. The research proves that using optimal proportions of vertical and horizontal oscillation frequencies allows creating a uniform surface structure of the blade airfoil profile. The first ever study of surface areas of a turbine 1st stage adjacent to orifices along the entry edge has shown the roughness increases by 1.5-1.7 times around the orifice.

\section{References}

1. A.P. Husu, U.R. Wittenberg, V.A. Palmov, Roughness of surfaces. Theoreticalprobabilistic approach. p. 344 (1975).

2. A.D. Abramov, Evaluation of surface roughness of optical-electronic method [text]/N.V. Nosov, I.A. Podsekin [and others]//Vestnik Samgtu. Series "Technical Sciences". - v.33, pp. 89-94, (2005).

3. A.D. Abramov, Study of surface roughness bobinowanie rollers on the basis of their autocorrelation functions [text]/A.D. Abramov, N.V. Nosov, V.I. Khaustov // Vestnik SSAU. A series of "Aviation and rocket-space technology", v. 3 (19), pp. $45-53$ (2009)

4. N.V. Nosov, Determination of surface roughness of the raceways of the bearings of the instrument using quasi-optimal correlation algorithm [text] / A.D. Abramov, A.I. Nikonov, etc.//Izvestiya Samara scientific center of RAS, v. 13, no. 4(3), pp. 645-651 (2011)

5. N.V. Nosov, Estimation of parameters of a microrelief of surfaces of details of machines based on correlation of quasi-optimal algorithms [text] / A.D. Abramov//Bulletin of computer and information technology, no. 9, pp. 19-25 (2016)

6. A.D. Abramov, A.I. Nikonov, N.V. Nosov, Method of monitoring surface roughness of the product. The patent for the invention № 2413179, G01B 11/30 (2006/01), G01N 21/93 (2006/01). Bull. No. 6, 27.02.2011.

7. A.D. Abramov, Evaluation of the microgeometry of the surface of the GTE blades based on the analysis of their autocorrelation functions [text] // Vestnik Samgtu. Series "Technical Sciences", no. 2 (20), pp. 117-123 (2007) 